\title{
Fluorescent vinyl and styryl coumarins: A comprehensive DFT study of structural, electronic and NLO properties
}

\author{
KIRAN AVHAD, AMOL JADHAV and NAGAIYAN SEKAR* \\ Department of Dyestuff Technology, Institute of Chemical Technology, Matunga, Mumbai, \\ Maharashtra 400 019, India \\ E-mail: n.sekar@ictmumbai.edu.in; nethi.sekar@gmail.com
}

MS received 30 July 2017; revised 18 September 2017; accepted 22 September 2017; published online 14 November 2017

\begin{abstract}
Nonlinear optical properties of 3-styryl and 3-vinyl coumarin dyes have been investigated with Density Functional Theory (DFT) using global hybrid $(\mathrm{GH})$ and range-separated hybrid (RSH) functionals. The performance of GHs - B3LYP, BHHLYP, PBE0, M06, M06L, M062X, and M06HF and RSHs - CAM-B3LYP, HISSbPBE, HSEH1PBE, wB97, wB97X, and wB97XD in combination with 6-311++G(d,p) basis set has been analyzed. Estimated (hyper) polarizability $\left(\alpha_{0}, \beta_{0}\right)$ obtained from the GHs - M06, M062X and PBE0 are in agreement with each other. The RSHs - wB97 and wB97X estimate very close values of $\beta_{0}$. The $\beta_{0}$ value of 3-styryl and 3-vinyl coumarins reaches the maximum as the bond length alternation and bond order alternation parameters tend to zero. Natural bond orbital analysis shows there is extensive charge transfer in the excited state leading to large value of $\beta_{0}$. The vibrational contribution to $\alpha_{0}$ and $\beta_{0}$ is significantly less when the donor is methoxy group and acceptor is nitro group in the 3-styryl coumarin. The dye, (E)-7-(diethylamino)-3-(4nitrostyryl)-2H-chromen-2-one (3c) is found to give the highest NLO response. An increasing electrophilicity originating from the decreased HOMO-LUMO band gap leads to an increase in $\alpha_{0}$ and $\beta_{0}$ in all the cases.
\end{abstract}

Keywords. BLA/BOA; coumarin vinyls and styryls; DFT; GHs and RSHs; nonlinear optical properties.

\section{Introduction}

Organic molecules with nonlinear optical (NLO) properties have wide range of applications because of their small dielectric constants, ${ }^{1}$ electro-optical (EO) modulation characteristics, ${ }^{2}$ ultrafast responses,${ }^{3}$ high optical damage thresholds, simple methods of preparation and low fabrication costs. ${ }^{4-7}$ The $\pi-\pi *$ transitions in organic molecules make them better candidates as NLO materials for wide bandwidth optoelectronic telecommunication systems in electronic/photonic integrated circuits, phased array radars, and in terahertz $(\mathrm{THz})$ and spectroscopy applications. ${ }^{8,9}$ Unlike geometric perturbations of central metal ion occurring in the crystalline inorganic NLO materials the electronic charge transfer across the organic molecules plays a key role ${ }^{10,11}$ allowing the optical response of NLO-active organic compounds much faster over the inorganic compounds. In this context, the higher second and third order NLO properties of simple organic molecular materials have been extensively studied. ${ }^{12-15}$

Past few decades have witnessed developments in terms of synthesis of a huge number of organic $\pi$ conjugated molecules with suitable molecular design strategies for better NLO materials. ${ }^{16}$ Many of these molecules bear donor and acceptor groups separated by a conjugated bridge (D- $\pi-A$ ) with a push-pull type of arrangement. ${ }^{17-22}$ NLO materials with good thermal and photostabilities are of great importance in photonics. ${ }^{23-26}$ Coumarin dyes are known for their outstanding charge mobility from donor to acceptor and therefore they have been studied for their NLO properties. ${ }^{27-33}$ Recently, pentaammineruthenium complex of coumarins 510 and 523 have been shown to have large hyperpolarizability values. ${ }^{32,34}$ Linear and NLO properties of substituted coumarins have been recently studied experimentally ${ }^{32,35}$ as well as using DFT computations. ${ }^{36,37}$ Thus, theoretical computations should

\footnotetext{
*For correspondence

Electronic supplementary material: The online version of this article (https://doi.org/10.1007/s12039-017-1392-1) contains supplementary material, which is available to authorized users.
} 
be able to throw light on the structure-property relationship of NLOphoric molecules, particularly the coumarin dyes. In the design of $\pi$ conjugated polymers and molecular NLO active materials, bond length alternation (BLA) is shown to be one of the important geometrical parameters. ${ }^{38-40}$ It has been shown that the trends in NLO properties obtained from electric field induced second harmonic generation (EFISHG) can be correlated with the BLA based on the geometry obtained from $\mathrm{X}$-ray crystallographic studies ${ }^{41,42}$ in comparison with the computational studies. . $^{1,40,43,44}$

In this paper, a benchmarking study has been done to understand the performance of hybrid functionals (GHs) as against range-separated hybrid functionals (RSHs) in computing the total polarizability $\left(\alpha_{0}\right)$ and static firstorder hyperpolarizability $\left(\beta_{0}\right)$ values of the coumarin dyes. The BLA, BOA parameter at ground state (GS) and excited state (ES) and $\beta_{0}$ values were computed from geometry optimized at B3LYP/6-311++G(d,p) level of theory. Also, a correlation is established between BLA and BOA parameters and hyperpolarizability $\left(\beta_{0}\right)$ values of 3-styryl and 3-vinyl coumarins. The charge transfer (CT) characteristics of these molecules have been established using natural bond orbital (NBO) analysis and molecular electrostatic potential (MEP) analysis using the same level of theory. The vibrational contribution to the $\alpha_{0}$ and $\beta_{0}$ values have been computed for the three series of coumarin derivatives namely $\mathbf{1 a}$ to $\mathbf{1 c}, \mathbf{2 a}$ to $\mathbf{2 c}$ and $\mathbf{3 a}$ to $\mathbf{3 c}$ in their ground state. The present study will possibly facilitate the design of new compounds with large magnitude linear and NLO response in organic materials.

\section{Computational details}

Density Functional Theory (DFT) computations ${ }^{45}$ were carried out with Gaussian 09 suit program. ${ }^{46}$ The GH functional B3LYP which uses Becke's three parameters (local, non-local) hybrid exchange functional with Lee-Yang-Parr correlation functional ${ }^{47-49}$ along with triple zeta basis set $6-311++G(d, p)^{50}$ was used for optimizing the ground state geometry. Time Dependent Density Functional Theory (TDDFT ${ }^{51}$ was used for obtaining vertical excitation (including triplet state) using the functionals B3LYP and CAM-B3LYP with the geometry as obtained above. DFT and TD-DFT computations in solvent environments were carried out using PCM model as implemented in Gaussian 09. ${ }^{52}$ The B3LYP/6$311++\mathrm{G}(\mathrm{d}, \mathrm{p})$ optimized geometry was used to populate NBOs and to construct the MEP plots. The total polarizability and static first order hyperpolarizability values were obtained using finite field approach ${ }^{53}$ as implemented in Gaussian 09 using both GHs and RSHs. The GHs used for polar computations are B3LYP, BHHLYP, PBE0, M06, M06L, M062X,
Table 1. Global hybrid (GHs) and range separated hybrid (RSHs) functionals with their HF \% exchange composition.

\begin{tabular}{lclcc}
\hline \multicolumn{2}{l}{ Global hybrids (GHs) } & & \multicolumn{2}{c}{ Rang separated hybrids (RSHs) } \\
\cline { 1 - 2 } \cline { 5 - 5 } Functional & HF $\%$ & & Functional & HF \% \\
\hline M06L & 0 & & HISSbPBE & - \\
B3LYP & 20 & & wB97 & 0 \\
PBE0 & 25 & & wB97X & 15 \\
M06 & 27 & & HSEH1PBE & $25-0$ \\
BHHLYP & 50 & & CAM-B3LYP & $19-65$ \\
M06-2X & 54 & & wB97X-D & $22-100$ \\
M06-HF & 100 & & - & - \\
\hline
\end{tabular}

and M06HF while the RSHs used are CAM-B3LYP, HISSbPBE, HSEH1PBE, wB9, wB97X, and wB97XD. In earlier benchmarking studies, RSH functionals have been found to perform much better than GHs for nonlinear optical properties based on comparison with highly accurate coupled-cluster models. ${ }^{54-64}$

The purpose of this work is the first instance to critically compare the performance of GHs versus RSHs in the computation of total polarizability $\left(\alpha_{0}\right)$ and the static first order hyperpolarizability $\left(\beta_{0}\right)$ of vinyl and styryl coumarins in the light of the fact that RSHs outperform. ${ }^{65,67,68}$ The GHs and RSHs used in the study with their best HF \% exchange composition are presented in Table 1.

The components of hyperpolarizability are defined as the coefficients in the Taylor series expansion of the energy in the external electric field. When the external electric field is weak and homogeneous, Taylor series expansion of the energy becomes Eq. 1.

$$
\begin{aligned}
E= & E^{0}-\mu_{1} F_{1}-\frac{1}{2} \alpha_{i j} F_{i} F_{j} \\
& -\frac{1}{6} \beta_{i j k} F_{i} F_{j} F_{k}+\frac{1}{24} \gamma_{i j k l} F_{i} F_{j} F_{k} F_{l}+\cdots
\end{aligned}
$$

where, $E^{0}$ is the energy of the unperturbed molecules, $\mu$ is the vector component of the dipole moment, $\alpha$ is the linear polarizability, $F_{i}$ is the field at the origin, $\mu_{i}, \alpha_{i j}, b_{i j k}$ and $c_{i j k l}$ are respectively the components of dipole moment, polarizability, the first hyperpolarizabilities and the second hyperpolarizabilities. The total static dipole moment $(\mu)$, mean polarizability $\left(\alpha_{0}\right)$, anisotropy of polarizability $(\Delta \alpha)$ and static total first order hyperpolarizability $\left(\beta_{0}\right)$ can be calculated using the $\mathrm{x}$, $\mathrm{y}$ and $\mathrm{z}$ components as: ${ }^{69}$

$$
\begin{aligned}
\mu= & \left(\mu_{x}^{2}+\mu_{y}^{2}+\mu_{z}^{2}\right)^{\frac{1}{2}} \\
\alpha_{0}= & \left(\frac{1}{3}\right)\left[\alpha_{x x}+\alpha_{y y}+\alpha_{z z}\right] \\
\Delta \alpha= & 2^{-\frac{1}{2}}\left[\left(\alpha_{x x}-\alpha_{y y}\right)^{2}+\left(\alpha_{y y}-\alpha_{z z}\right)^{2}\right. \\
& \left.+\left(\alpha_{z z}-\alpha_{x x}\right)^{2}+6 \alpha_{x x}^{2}\right]^{\frac{1}{2}} \\
\beta_{t o t a l}= & {\left[\left(\beta_{x x x}+\beta_{x y y}+\beta_{x z z}\right)^{2}+\left(\beta_{y x x}+\beta_{y y y}+\beta_{y z z}\right)^{2}\right.} \\
& \left.+\left(\beta_{z x x}+\beta_{z y y}+\beta_{z z z}\right)^{2}\right]^{\frac{1}{2}}
\end{aligned}
$$


<smiles>C=Cc1cc2ccccc2oc1=O</smiles><smiles>O=c1oc2ccccc2cc1/C=C/c1ccccc1</smiles>

$2 a$<smiles>O=c1oc2ccccc2cc1/C=C/c1ccc([N+](=O)[O-])cc1</smiles><smiles>C=Cc1cc2ccc(OC)cc2oc1=O</smiles><smiles>COc1ccc2cc(/C=C/c3ccccc3)c(=O)oc2c1</smiles>

2b<smiles>C=Cc1cc2ccc(N(CC)CC)cc2oc1=O</smiles><smiles>CCN(CC)c1ccc2cc(/C=C/c3ccccc3)c(=O)oc2c1</smiles>

2c
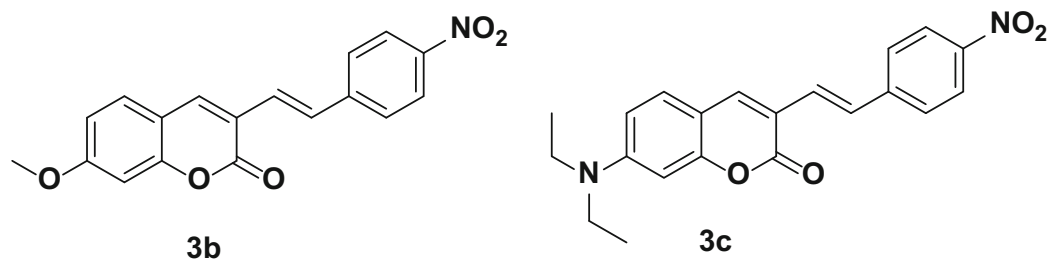

Figure 1. Structures of vinyl and styryl coumarins.

The values of total static dipole moment $(\mu)$, the mean polarizability $\left(\alpha_{0}\right)$ and the mean static total first order hyperpolarizability $\left(\beta_{0}\right)$ of the dyes 1a-1c, 2a-2c and 3a-3c (Figure 1) calculated in gas and acetonitrile solvent using Equations (2-5) respectively with the GHs and range RSHs using 6$311++\mathrm{G}(\mathrm{d}, \mathrm{p})$ basis sets. The CT parameters are defined as the delocalization energy $\mathrm{E}(2)$ and describe the interactions between donors (i) and acceptor (j). They are given by,

$E(2)=q_{i} \frac{F(i, j)^{2}}{\varepsilon_{j}-\varepsilon_{i}}$

Where, $\mathrm{q}_{i}$ is the occupation number of the donor orbital, $\varepsilon_{i}$ and $\varepsilon_{j}$ are diagonal elements and equal to the orbital energies. Finally, $\mathrm{F}(i, j)$ is the off-diagonal (off) of the Fock matrix.

In addition, we also studied the HOMO-LUMO energy band gap, global hardness $\eta$, Global softness S, Electrophilicity index $\omega$, and energy of the intercrossing system ( $\left.\Delta \mathrm{E}_{\mathrm{ISC}}\right)$.

\section{Results and Discussion}

\subsection{Geometries in ground state $\left(S_{0}\right)$ and lowest lying excited singlet $\left(S_{1}\right)$}

The dyes 1a-1c, 2a-2c and 3a-3c were optimized in their ground $\left(\mathrm{S}_{0}\right)$ and lowest lying singlet excited $\left(\mathrm{S}_{1}\right)$ states with the help of DFT and TD-DFT using B3LYP/6-311++G(d,p) in the gas phase and acetonitrile environment. For illustration, the results of optimized geometry parameters of the dyes $\mathbf{1 a - 1 c}, \mathbf{2 a - 2 c}$ and $\mathbf{3 a -}$ $\mathbf{3 c}$ in acetonitrile are presented in Table S1. The dyes are found to be perfectly planar in $\mathrm{S}_{0}$ and $\mathrm{S}_{1}$ state revealing the effective ICT character (Figure 2). NLO response in $\mathrm{D}-\pi-\mathrm{A}$ system is well understood by molecular geometry parameter of BLA/BOA. BLA and BOA of the conjugated chain were calculated as reported. ${ }^{70}$ Optimized structure of 3c (Figure 2) shows that major single bond length gets shortened for the bonds $\mathrm{N}_{30}-\mathrm{C}_{11}, \mathrm{C}_{10^{-}}$ $\mathrm{C}_{8}, \mathrm{C}_{3}-\mathrm{C}_{4}, \mathrm{C}_{5}-\mathrm{C}_{15}, \mathrm{C}_{18}-\mathrm{C}_{20}, \mathrm{C}_{22}-\mathrm{C}_{25}, \mathrm{C}_{27}-\mathrm{N}_{47}$, the values are respectively $0.009,0.005,0.004,0.013,0.008$, $0.002,0.031 \AA$. The incremental lengthenings in double bonds $\mathrm{C}_{10}-\mathrm{C}_{11}, \mathrm{C}_{8}-\mathrm{C}_{3}, \mathrm{C}_{4}-\mathrm{C}_{5}, \mathrm{C}_{15}-\mathrm{C}_{18}, \mathrm{C}_{20}-\mathrm{C}_{22}, \mathrm{C}_{25}-\mathrm{C}_{27}$ as compared to the $\mathrm{S}_{0}$ state are respectively $0.005,0.007$, $0.010,0.015,0.005,0.010 \AA$. Therefore the shortening and lengthening in between $\sigma$ and $\pi$ bonds are observed due to their partial overlap of $\pi$ bond character in the donor-acceptor system. Similar results are observed for the other dyes, 1a-1c, $\mathbf{2 a - 2 c}$, and 3a-3b. The values are presented in Table S2a, S2b, and S2c. The BLA values for all the dyes are positive and tend to be zero, which indicate that the molecular structure is approaching towards cyanine limit $(\mathrm{BLA}=0)$ from polyene limit (BLA 0.4-0.6). The BOA values of coumarin dyes are negative and tend to be zero, suggesting that the molecular structure is approaching towards cyanine limit (BOA $=0$ ) from polyene limit $(\mathrm{BOA}=\sim 0.6)$. Further, the values of BLA and BOA in $S_{0}$ state are more than in $\mathrm{S}_{1}$ state which signifies that $\mathrm{S}_{1}$ state is more polarized than $\mathrm{S}_{0}$ state. This increase in polarization in the first excited state is responsible for the lowering of HOMOLUMO energy gap. BLA and BOA results indicate that the dyes show more cyanine character which is desirable for enhanced NLO response. 


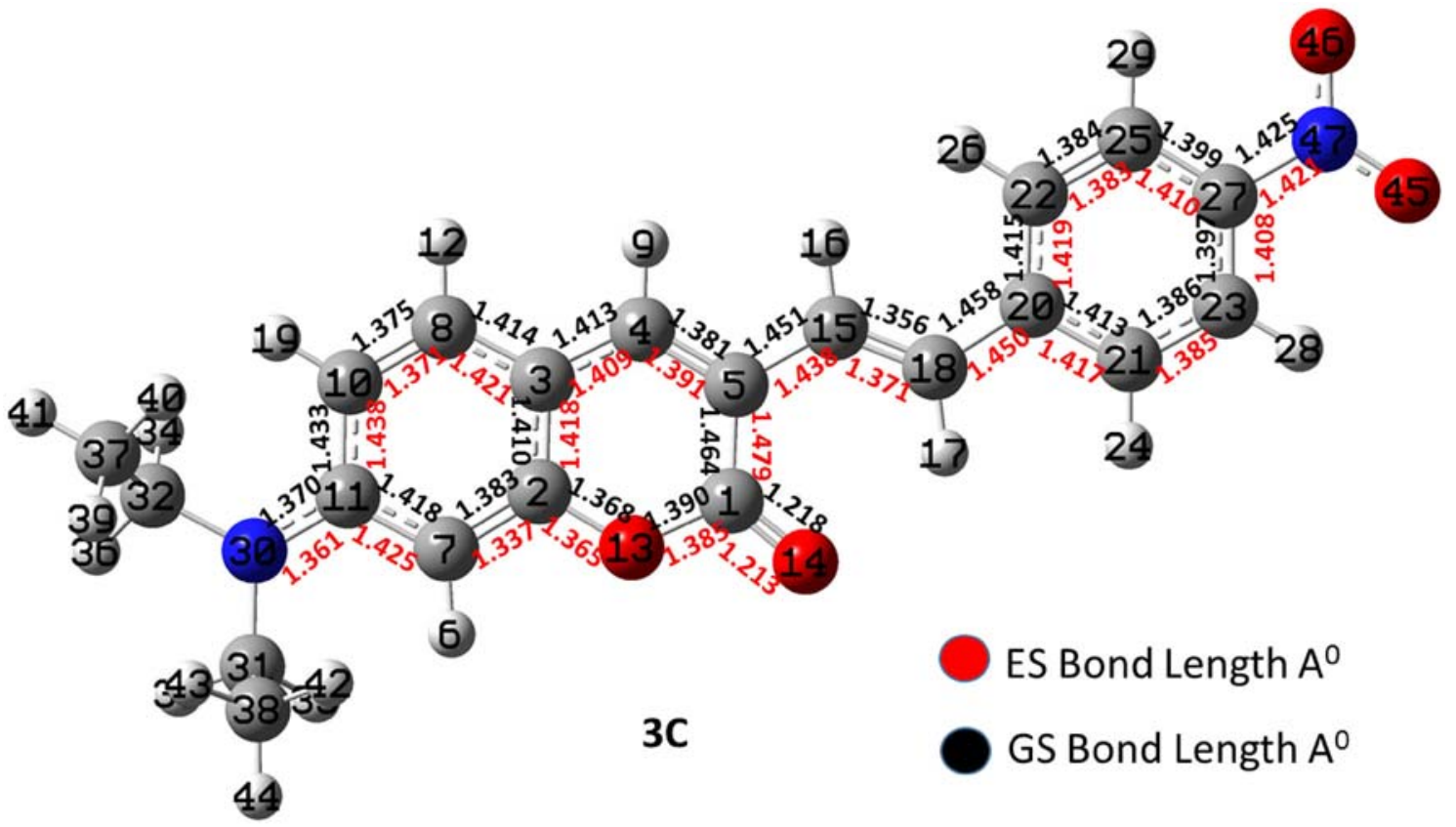

Figure 2. Optimized geometry of $\mathbf{3 c}$ in acetonitrile medium at B3LYP/6-311++G(d,p) level of theory.

Table 2. Optical data of dyes 1a-1c, $\mathbf{2 a - 2 c}$ and 3a-3c, ${ }^{\mathrm{a}}$ vertical excitation (nm), ${ }^{\mathrm{b}}$ oscillator strength and ${ }^{c}$ experimental absorption (nm) data in the gas phase and solvent acetonitrile.

\begin{tabular}{|c|c|c|c|c|c|c|c|c|}
\hline \multirow[t]{2}{*}{ Dye } & \multirow[t]{2}{*}{ Phase } & \multicolumn{3}{|c|}{ B3LYP/6-311++G(d,p) } & \multicolumn{3}{|c|}{ CAM-B3LYP/6-311++G(d,p) } & \multirow[t]{2}{*}{ Exp. $\lambda_{\max }(\mathrm{nm})^{c}$} \\
\hline & & $\lambda_{\max }(\mathrm{nm})^{\mathrm{a}}$ & $f^{b}$ & $\mathrm{OC}(\%) \mathrm{H} \rightarrow \mathrm{L}$ & $\overline{\lambda_{\max }(\mathrm{nm})^{\mathrm{a}}}$ & $f^{b}$ & $\mathrm{OC}(\%) \mathrm{H} \rightarrow \mathrm{L}$ & \\
\hline \multirow[t]{2}{*}{$1 \mathrm{a}$} & Gas & 323 & 0.437 & 87.73 & 302 & 0.522 & 90.98 & 326 \\
\hline & ACNE & 329 & 0.598 & 94.12 & 308 & 0.677 & 94.08 & \\
\hline \multirow[t]{2}{*}{$1 b$} & Gas & 333 & 0.692 & 82.05 & 311 & 0.710 & 94.25 & 333 \\
\hline & ACNE & 346 & 0.761 & 97.58 & 323 & 0.851 & 96.07 & \\
\hline \multirow[t]{2}{*}{$1 \mathrm{c}$} & Gas & 365 & 0.731 & 97.16 & 335 & 0.844 & 95.44 & 400 \\
\hline & ACNE & 392 & 0.844 & 98.31 & 359 & 0.984 & 96.15 & \\
\hline \multirow[t]{2}{*}{$2 \mathrm{a}$} & Gas & 377 & 0.952 & 98.27 & 340 & 1.128 & 95.27 & 351 \\
\hline & ACNE & 388 & 1.066 & 99.03 & 347 & 1.270 & 95.24 & \\
\hline \multirow[t]{2}{*}{$2 b$} & Gas & 381 & 1.080 & 98.65 & 346 & 3.584 & 95.67 & 366 \\
\hline & ACNE & 394 & 1.218 & 99.23 & 356 & 1.368 & 95.70 & \\
\hline \multirow[t]{2}{*}{$2 c$} & Gas & 403 & 1.294 & 98.87 & 364 & 1.418 & 95.47 & 421 \\
\hline & ACNE & 428 & 1.419 & 99.23 & 386 & 1.542 & 95.36 & \\
\hline \multirow[t]{2}{*}{$3 \mathrm{a}$} & Gas & 401 & 1.122 & 98.28 & 350 & 1.382 & 92.37 & 371 \\
\hline & ACNE & 447 & 1.102 & 99.56 & 374 & 1.521 & 88.35 & \\
\hline \multirow[t]{2}{*}{$3 b$} & Gas & 422 & 1.116 & 98.79 & 362 & 1.488 & 88.79 & 392 \\
\hline & ACNE & 481 & 1.075 & 99.70 & 390 & 1.621 & 83.32 & \\
\hline \multirow[t]{2}{*}{$3 \mathrm{c}$} & Gas & 468 & 1.101 & 99.27 & 405 & 1.621 & 77.28 & 459 \\
\hline & ACNE & 566 & 1.029 & 99.99 & 431 & 1.811 & 75.90 & \\
\hline
\end{tabular}

\subsection{Vertical Excitation}

The values of vertical excitation obtained from TDB3LYP/6-311++G(d,p) and TD- CAM-B3LYP/6-311 $++\mathrm{G}(\mathrm{d}, \mathrm{p})$, the oscillator strengths $(f)$ and experimental absorption $\left(\lambda_{\max }\right)^{71}$ data of dyes (1a-1c, $\mathbf{2 a - 2 c}$ and $\mathbf{3 a -}$ 3c) are summarized in Table 2 . The presence of donor group at 7 positions and acceptor at 3 positions gives red-shifted absorption was found in the trends in the computed vertical excitation values. The dyes 1a-1c, $2 \mathbf{a}$ 2c, and 3a-3c have shown absorption between $320 \mathrm{~nm}$ and $459 \mathrm{~nm}$ and vertical excitation in the range of 323 $\mathrm{nm}$ to $566 \mathrm{~nm}$ and $302 \mathrm{~nm}$ to $431 \mathrm{~nm}$ using B3LYP and CAM-B3LYP functionals respectively. Among these two functionals, B3LYP shows reasonably accurate results of absorption for dyes $\mathbf{1 a}, \mathbf{1 b}, \mathbf{1 c}$ and $\mathbf{2 c}$ while 


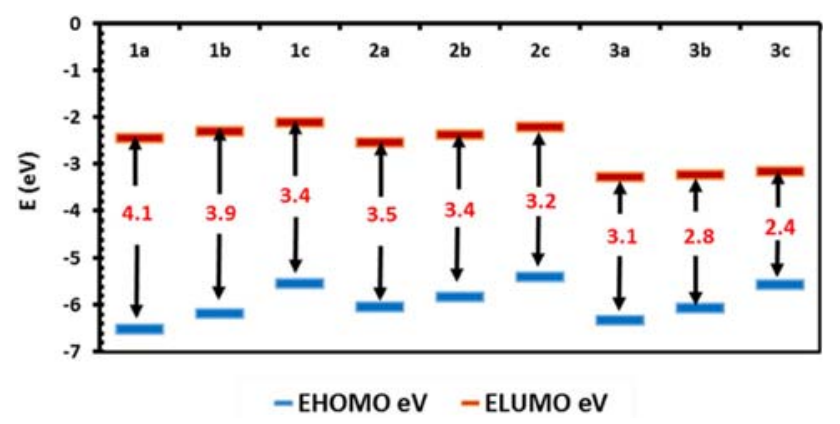

Figure 3. HOMO-LUMO energy level diagram $(\mathrm{eV})$ of dyes 1a-1c, 2a-2c and 3a-3c in acetonitrile solvent considered at the B3LYP/6-311++G(d,p) level.

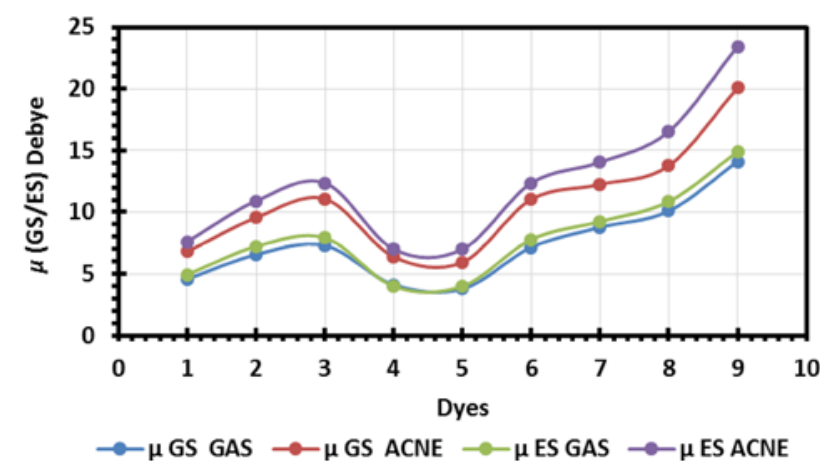

Figure 4. Dipole moment ( $\mu$ in Debye) graph in the ground state $\left(\mathrm{S}_{0}\right)$ and excited state $\left(\mathrm{S}_{1}\right)$ in gas and solvent acetonitrile (ACNE) phase.

overestimates the absorption for dyes $\mathbf{2 a}, \mathbf{2} \mathbf{b}, \mathbf{3 a}, \mathbf{3 b}$, and 3c. The values obtained using RSH, CAM-B3LYP functional are reasonably accurate with lower discrepancy as compared to the B3LYP functional. In the $-\mathrm{NO}_{2}$ group containing dyes donor strength increases in the order $-\mathrm{H}<-\mathrm{OCH}_{3}<-\mathrm{N}\left(\mathrm{CH}_{2} \mathrm{CH}_{3}\right)_{2}$ explaining trends in redshifted absorption as well as lowering HOMO-LUMO energy gap (Figure 3).

\subsection{Dipole moment $(\mu)$ at ground state $\left(S_{0}\right)$ and excited state $\left(S_{1}\right)$}

The dipole moments of $\mathrm{S}_{0}$ and $\mathrm{S}_{1}$ geometries were obtained from DFT and TD-DFT computations using the functional B3LYP and the basis set $6-311++\mathrm{G}(\mathrm{d}, \mathrm{p})$. The results are summarized in Table $\mathrm{S} 3$. The plots of $\mu$ of $S_{0}$ state geometries against the $\mu$ of $S_{1}$ state geometry of all the dyes are shown in Figure 4. It is evident that the trends are almost similar in all the cases. As the length of $\pi$-conjugation between donor and acceptor (3c) increases the $\mu$ of $S_{1}$ state increases, which shows that the $S_{1}$ state is more polar than $S_{0}$ state. Higher the value of $\mu$ more is the effective charge transfer from $\mathrm{N}, \mathrm{N}$-diethylamine donor moiety to the acceptor $-\mathrm{NO}_{2}$ which in this kind of molecules is further confirmed by the distribution of electron density at HOMO and LUMO. Moreover, an increase in the ratio, $\mu_{e} / \mu_{g}$ is also accompanied by a decrease in HOMO-LUMO gap leading to a red shift in emission as well as effective charge transfer. The static $\mu$ values computed using GHs and RSHs (Table S4) reveal the same trend. In case of $3 \mathbf{c}$ having both $\mathrm{NO}_{2}$ and dimethylamino group in conjugation, the highest $\mu$ was observed. As expected the donor strength increases in the order of $-\mathrm{H}<-\mathrm{OCH}_{3}<-$ $\mathrm{N}\left(\mathrm{CH}_{2} \mathrm{CH}_{3}\right)_{2}$ in the dyes $\mathbf{1 a - 1 c}<\mathbf{2 a - 2 c}<\mathbf{3 a - 3 c}$. The ratios of dipole moment between $\mathrm{S}_{0}$ and $\mathrm{S}_{1}$ states suggest that the dyes are more polar in the $S_{1}$ state (Table $S 3$ ).

\subsection{Charge Transfer Characteristics}

3.4a Frontier molecular orbitals (FMOs) approach: Frontier molecular orbital (FMOs) analysis helps in understanding the nature of intramolecular charge separation, electronic excitation and electron density transition in a molecule. The HOMO-LUMO electron counterplots of dyes 1a-1c, $\mathbf{2 a - 2 c}$ and $\mathbf{3 a - 3} \mathbf{c}$ were calculated using B3LYP/6-311++G(d,p) and are shown in Figure $\mathrm{S} 1$. The charge transfer (CT) performance in dyes is well understood by the overlap of atomic orbitals involved in the electronic transitions, i.e. mainly from HOMO to LUMO which is associated with a change in dipole moment. From the HOMO-LUMO plots, electron densities in HOMO and LUMO are equally populated in dyes containing no substituents at 7 positions (1a, $\mathbf{2 a}$, 3a) which indicate that there is no efficient $\mathrm{CT}$ character in this cases. On the other hand, the electron density is spread all over the molecule and density migrates to LUMO when the molecules are functionalized with donor groups, $-\mathrm{OCH}_{3}$ and $-\mathrm{N}\left(\mathrm{CH}_{2} \mathrm{CH}_{3}\right)_{2}$. The results indicate that there is an efficient intramolecular charge transfer (ICT) and charge separation in this cases. Therefore, the facility of CT in dyes 1a-1c, 2a-2c and 3a-3c increases in the sequences of donors, $-\mathrm{H}<-\mathrm{OCH}_{3}<-$ $\mathrm{N}\left(\mathrm{CH}_{2} \mathrm{CH}_{3}\right)_{2}$. From the above observations, it is evident that in the donor substituted molecules the energy of HOMO increases while the energy of LUMO decreases leading to red shifted absorption as well as emission. It can be concluded that the dye $\mathbf{3 c}$ having a strong donor, $-\mathrm{N}\left(\mathrm{CH}_{2} \mathrm{CH}_{3}\right)_{2}$ and strong acceptor $\mathrm{NO}_{2}$ possess efficient $\mathrm{CT}$ character.

\section{4b Natural charges and natural bond orbital (NBO)} analysis from Fock Matrix: Natural charges in the ground state, as well as excited state, enabled to understand the intramolecular charge distribution and interactions. The natural charges on selected atoms within the dyes $\mathbf{1 c}, \mathbf{2 c}$ and $\mathbf{3 c}$ have been shown in Table 3 and similarly, for remaining dyes $(\mathbf{1 a}, \mathbf{1 b}, \mathbf{2 a}, \mathbf{2 b}, \mathbf{3 a}$, and 
Table 3. Natural charges on selected atoms of dyes $1 \mathbf{c}, \mathbf{2 c}$ and $3 \mathbf{c}$ in acetonitrile medium.

\begin{tabular}{lccccc}
\hline Atom No & $1 \mathrm{c}$ & Atom No & $2 \mathrm{c}$ & Atom No & $3 \mathrm{c}$ \\
\hline N18 & 0.00411 & $\mathrm{~N} 31$ & 0.00592 & $\mathrm{~N} 30$ & 0.00642 \\
C9 & 0.00541 & $\mathrm{C} 11$ & 0.00645 & $\mathrm{C} 11$ & 0.00639 \\
C17 & -0.00463 & $\mathrm{C} 27$ & 0.00039 & $\mathrm{C} 27$ & 0.00464 \\
O11 & -0.00175 & O13 & -0.00100 & N47 & -0.02849 \\
C1 & -0.01116 & C1 & -0.00575 & O45 & -0.01162 \\
C10 & -0.00287 & O14 & -0.00304 & O46 & -0.01159 \\
\hline
\end{tabular}

Table 4. Selected second-order perturbation energies E(2) (Donor $\rightarrow$ Acceptor $\pi$ interactions) of dye $\mathbf{3 c}$ in acetonitrile medium.

\begin{tabular}{|c|c|c|c|c|c|c|c|c|}
\hline \multirow[t]{2}{*}{ Donor(i) } & \multirow[t]{2}{*}{ Type } & \multirow[t]{2}{*}{$\mathrm{ED}^{[\mathrm{a}]}(\mathrm{e})$} & \multirow[t]{2}{*}{ Acceptor (j) } & \multirow[t]{2}{*}{ Type } & \multirow[t]{2}{*}{$\operatorname{ED}^{[a]}(\mathrm{e})$} & \multirow{2}{*}{$\frac{\mathrm{E}^{(2)[\mathrm{b}]}}{[\mathrm{kJ} / \mathrm{mol}]}$} & \multirow{2}{*}{$\begin{array}{l}\mathrm{E}(\mathrm{j})-\mathrm{E}(\mathrm{i})^{[\mathrm{c}]} \\
{[\text { a.u.] }}\end{array}$} & \multirow{2}{*}{$\frac{F(i, j)^{[d]}}{\text { [a.u.] }}$} \\
\hline & & & & & & & & \\
\hline \multirow[t]{8}{*}{ N30 } & \multirow[t]{8}{*}{$\mathrm{LP}(1)$} & \multirow[t]{8}{*}{1.68951} & $\mathrm{C} 4-\mathrm{C} 5$ & $\pi^{*}$ & 0.01723 & 24870.71 & 1.4 & 5.71 \\
\hline & & & C5 - C 15 & $\pi^{*}$ & 0.02244 & 1375.25 & 7.37 & 3.071 \\
\hline & & & C7 - C11 & $\pi^{*}$ & 0.01989 & 173.86 & 9.02 & 1.153 \\
\hline & & & C18 - C20 & $\pi^{*}$ & 0.02502 & 27.17 & 8.3 & 0.458 \\
\hline & & & C23 - C27 & $\pi^{*}$ & 0.02237 & 1481.16 & 8.31 & 3.385 \\
\hline & & & C27 - N47 & $\pi^{*}$ & 0.10153 & 10370.98 & 3.39 & 5.591 \\
\hline & & & O45 - N47 & $\pi *$ & 0.055 & 922.24 & 9.89 & 2.887 \\
\hline & & & O46 - N47 & $\pi^{*}$ & 0.05471 & 2300.14 & 7.22 & 3.975 \\
\hline $\mathrm{C} 4-\mathrm{C} 5$ & $\pi$ & 1.97419 & C7 - C11 & $\pi^{*}$ & 0.01989 & 76.27 & 0.04 & 0.053 \\
\hline \multirow[t]{2}{*}{ C15 - C18 } & \multirow[t]{2}{*}{$\pi$} & \multirow[t]{2}{*}{1.97473} & $\mathrm{C} 23-\mathrm{C} 27$ & $\pi^{*}$ & 0.02237 & 29287.67 & 0.04 & 0.983 \\
\hline & & & $\mathrm{O} 45$ - N47 & $\pi^{*}$ & 0.055 & 594.93 & 1.62 & 0.902 \\
\hline \multirow[t]{3}{*}{ C27 - N47 } & \multirow[t]{3}{*}{$\pi$} & \multirow{3}{*}{1.98861} & C7 - C11 & $\pi^{*}$ & 0.01989 & 833 & 0.09 & 0.275 \\
\hline & & & C15 - C18 & $\pi^{*}$ & 0.01447 & 34.59 & 0.98 & 0.164 \\
\hline & & & O45 - N47 & $\pi^{*}$ & 0.055 & 616.48 & 0.96 & 0.693 \\
\hline O45 - N47 & $\pi$ & 1.99575 & O45 - N47 & $\pi^{*}$ & 0.055 & 201.3 & 2.68 & 1.115 \\
\hline
\end{tabular}

Where, ${ }^{[a]} \mathrm{ED}$ is the electron density, ${ }^{[\mathrm{b}]} \mathrm{E}(2)$ means energy of hyperconjugative interactions (stabilization energy), ${ }^{[c]}$ Energy difference between donor and acceptor $i$ and $j \mathrm{NBO}$ orbitals, ${ }^{[\mathrm{d}]} \mathrm{F}(\mathrm{i}, \mathrm{j})$ is the Fock matrix element between i and j NBO orbitals.

3b) are shown in Table S5. It is as expected and found that the donor fragment carries a positive charge while acceptor fragment has a negative charge. The positive natural charge on $\mathrm{N}$-atom indicates that the moiety carrying $\mathrm{N}$-atom is an effective electron donor unit while the one having the negative value represents the good electron acceptor unit. The dyes $1 \mathbf{1 c}, \mathbf{2 c}$ and $3 \mathbf{c}$ show more NBO charges on the electron donor group as compared to the other dyes hence the dyes $1 \mathbf{c}, \mathbf{2 c}$ and $\mathbf{3 c}$ exhibit strong electron transfer towards acceptor. The second order Fock matrix analysis has been constructed to investigate the donor-acceptor interactions and stability of the coumarin dyes using B3LYP/6-311++G(d,p) level of theory, in order to comprehend the intramolecular charge transfer and delocalization of electron density. Higher the $E(2)$ value more the intensive molecular interaction between the electron donor and electron acceptor leading to a greater extent of conjugation in the system. These interactions are observed as an increase the electron density on $\mathrm{C}=\mathrm{C}$ bond to the antibonding orbitals of the $\mathrm{C}=\mathrm{C}$ bond. Table 4 shows that there exists intramolecular hyperconjugative interaction between donor and acceptor for 3c. Similarly, for the other dyes, the values have been listed in Table S6. Strong intramolecular hyper conjugative interaction of the $\pi$ electrons of $\mathrm{C}=\mathrm{C}$ to the $\mathrm{C}=\mathrm{C}^{*}$ bond orbital of the conjugated system leads to stabilization of the molecule. It has been observed that the hyperconjugative interaction of $\pi$ electrons of $\mathrm{N}_{1}$ (LP) with the $\pi^{*}$ of the $\mathrm{C}_{4}-\mathrm{C}_{5}$ bond increases the electron density by 0.01723 leading to the stabilization energy of $\sim 24870.71 \mathrm{~kJ} / \mathrm{mol}$. The nitrogen of $\mathrm{N}, \mathrm{N}$-diethylamino group, $\mathrm{N}_{1}$ (LP) is also conjugated with the C5-C15, C7-C11, C18-C20, C23-C27, C27-N47, O45-N47 and O46-N47 with their stabilization energies $1375.25,173.86,27.17,1481.16$, $10370.98,922.24$ and $2300.24 \mathrm{~kJ} / \mathrm{mol}$. respectively. In 


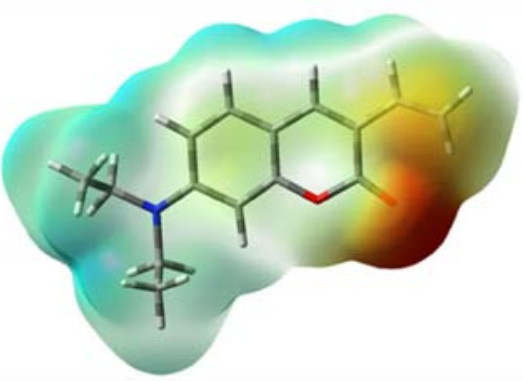

$1 \mathrm{c}$

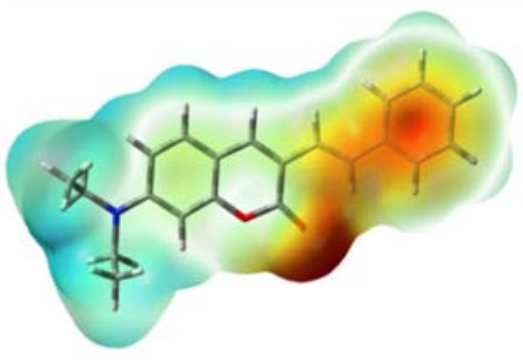

2c

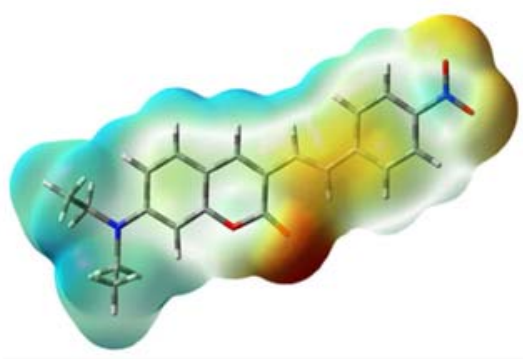

3c

Figure 5. MEP surface plots of coumarin dyes 1c, 2c and 3c.

this regard, the most energetic interaction of $\mathrm{C}_{15}-\mathrm{C}_{18}$ conjugates with $\pi^{*}$ of $\mathrm{C} 23-\mathrm{C} 27$ and $\mathrm{O} 45-\mathrm{N} 47$ of 29287.67 and $594.93 \mathrm{~kJ} / \mathrm{mol}$. Also, the planarity of the nitro group with the donor group and phenyl ring increases the conjugation between them which signifies the electron delocalization from the donor to the acceptor. These intramolecular interactions within the $\pi$ to $\pi^{*}$ are responsible for the $\mathrm{CT}$ from donor to acceptor end leads to polarization and optical nonlinearity within the molecule.

3.4c Molecular electrostatic potential (MEP) analysis: MEP analysis is an important tool in describing the reactivity of molecules. It gives information on shape, size, charge density, polarity, and site of chemical reactivity of molecules. The 3D MEP plots of 1c, 2c and 3c are constructed from B3LYP/6- 311++G(d,p) optimized geometry with the help of visualization program, Gauss View 5.0 and shown in Figure 5. MEP values of 1c, $2 \mathbf{c}$ and $\mathbf{3 c}$ are $\pm 0.101, \pm 0.00957$ and \pm 0.00894 a.u. respectively. MEP plot shows that negative potential site (electrophilic region) is located over carbonyl group as well as a double bond in 1c and the positive potential sites (nucleophilic regions) are found around the hydrogen atoms. In case of $\mathbf{2 c}$, a negative potential is located over the carbonyl group along with $\pi$-bridge and phenyl ring. But in case of $\mathbf{3 c}$, the electron density is located on carbonyl group, $\pi$-bridge and nitro group.

3.4d Triplet state populations and electrophilicity index: The triplet state of a molecule has a lower energy compared to the singlet state. The TD-DFT computation showed that there are three triplet states between $S_{0}$ and $\mathrm{S}_{1}$ states in $\mathbf{1 a}$ and $\mathbf{1 b}$, while there were only two such triplet states in $\mathbf{2 a}, \mathbf{2 b}, \mathbf{2 c}, \mathbf{3 a}$ and $\mathbf{3 b}$. However, there was only one triplet state lying between $S_{0}$ and $S_{1}$ in 1c and 3c. The energy intersystem crossing, $\Delta \mathrm{E}_{\mathrm{ISC}}$ which is the energy difference between $S_{1}$ and the triplet state closer to $\mathrm{S}_{1}$, was calculated in each case and shown in
Table S7 along with the quantum yield values. It turns out that substitutions on 7 and 3 positions directly influence the fluorescence quantum yield of coumarin dyes. The fluorescence quantum yield of $\mathbf{3 c}$ is lower $(<0.01)$ as compared to the other dyes, which is in the good agreement with the lower $\Delta \mathrm{E}_{\mathrm{ISC}}$ values. When there are no donor and acceptor groups as in 1a, 2a and 3a the $\Delta \mathrm{E}_{\mathrm{ISC}}$ values are higher which leads to an increase in quantum yield. The $\Delta \mathrm{E}_{\mathrm{ISC}}$ values in each series are in the order $\mathbf{1 a}>\mathbf{1 b}>\mathbf{1 c}, \mathbf{2} \mathbf{a}>\mathbf{2 b}>\mathbf{2} \mathbf{c}$ and $\mathbf{3 a}>\mathbf{3 b}>$ 3c.

The chemical stability of a dye depends on its hardness and softness. From the HOMO - LUMO energy band gap, one can find whether the molecule is hard or soft. ${ }^{72,73}$ The dyes having the high energy band gap lead to more hardness and vice versa. The hardness of a dye is inversely proportional to the electrophilicity index $(\omega)$ (Table S7). The $\omega$ can be defined as an electrophilic power of the molecule which signifies the energy lowering associated with the maximum electron flow between donor and acceptor orbitals. From the Table S7, it is seen that the energy band gap $\left(\mathrm{E}_{\mathrm{L}}-\mathrm{E}_{\mathrm{H}}\right)$ of the dyes are in good agreement with $\omega$ and the trend is $1 \mathbf{a}>\mathbf{1 c}, \mathbf{2 a}>\mathbf{2 c}$ and $\mathbf{3 a}<\mathbf{3 c}$. The hardness of a molecule can be determined by the formula,

$\eta=\frac{(-\varepsilon H O M O+\varepsilon L U M O)}{2}$

Where, $\eta=$ hardness of molecule, $\varepsilon$ HOMO and $\varepsilon$ LUMO are the energies of the HOMO and LUMO orbitals respectively.

\subsection{Polarizability and hyperpolarizability}

The total polarizability $\left(\alpha_{0}\right)$, polarizability anisotropy $(\Delta \alpha)$ and the static first order hyperpolarizability $\left(\beta_{0}\right)$ were calculated using global hybrid $(\mathrm{GH})$ and range separated hybrid (RSH) functionals with $6-311++\mathrm{G}(\mathrm{d}, \mathrm{p})$ basis set as implemented in Gaussian 09. The results of $\alpha_{0}, \Delta \alpha, \beta_{0}$ and mean absolute error (MAE) of each dye 


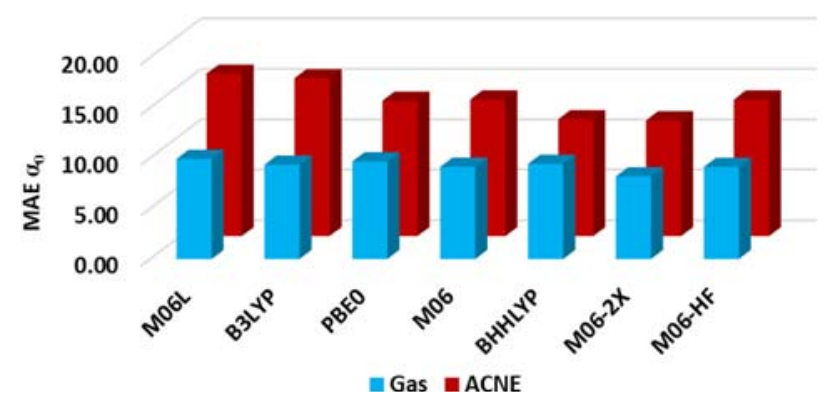

Figure 6. Polarizability $\left(\alpha_{0} \times 10^{-24}\right.$ e.s.u. $)$ mean absolute error (MAE) in the gas phase and solvent acetonitrile (ACNE) obtained from global hybrid functions (GHs).

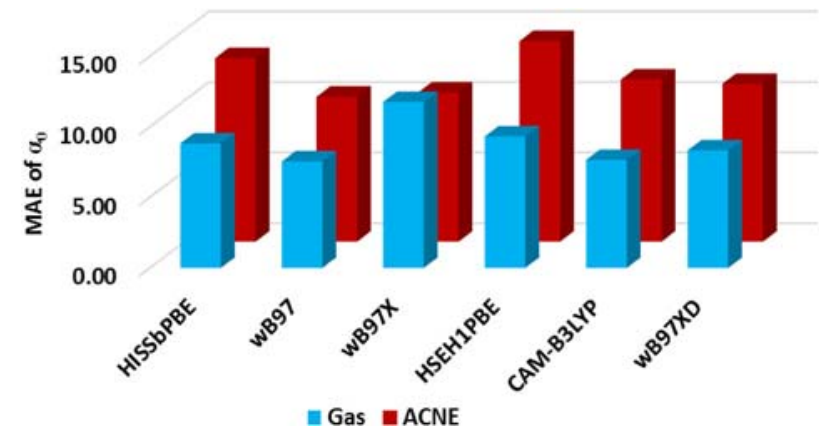

Figure 7. Mean absolute error (MAE) of polarizability $\left(\alpha_{0} \times 10^{-24}\right.$ e.s.u. $)$ in the gas phase and solvent acetonitrile (ACNE) obtained from range separated hybrid functionals (RSHs).

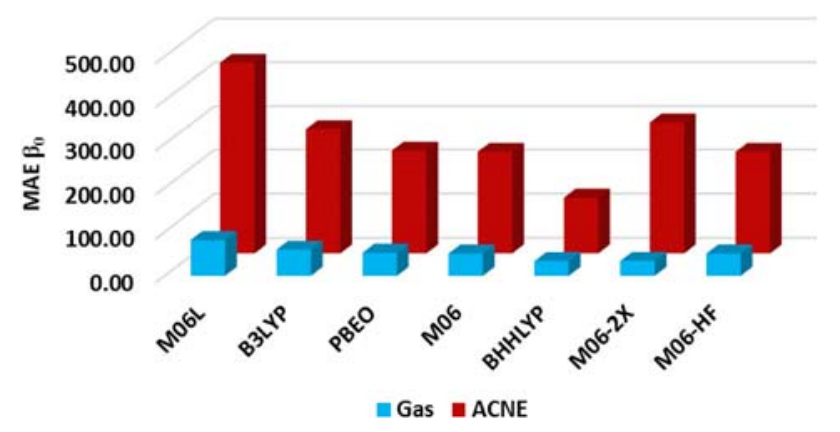

Figure 8. Hyperpolarizability $\left(\beta_{0} \times 10^{-30}\right.$ e.s.u. $)$ mean absolute error (MAE) in the gas phase and solvent acetonitrile (ACNE) by global hybrid functions (GHs).

in every case are calculated in the gas phase, as well as the inclusion of solvent (acetonitrile), are shown in Table S8, S9, S10, S11, S12, and S13. The comparative results of MAE with respect to each functional are shown in Figures 6, 7, 8 and 9.

It is clearly observed that the $\mathbf{1 a}, \mathbf{1 b}, \mathbf{1 c}$ dyes show enhanced $\alpha_{0}, \Delta \alpha$, and $\beta_{0}$ with the substitution pattern as $-\mathrm{H}<-\mathrm{OCH}_{3}<-\mathrm{N}\left(\mathrm{CH}_{2} \mathrm{CH}_{3}\right)_{2}$ group. A similar trend was observed for styryl dyes $\mathbf{2 a}, \mathbf{2 b}$ and $\mathbf{2 c}$ where one of the $\mathrm{H}$ in the terminal carbon of the vinyl is replaced by phenyl, as well as in $\mathbf{3 a}, \mathbf{3 b}$ and $\mathbf{3 c}$ where phenyl ring

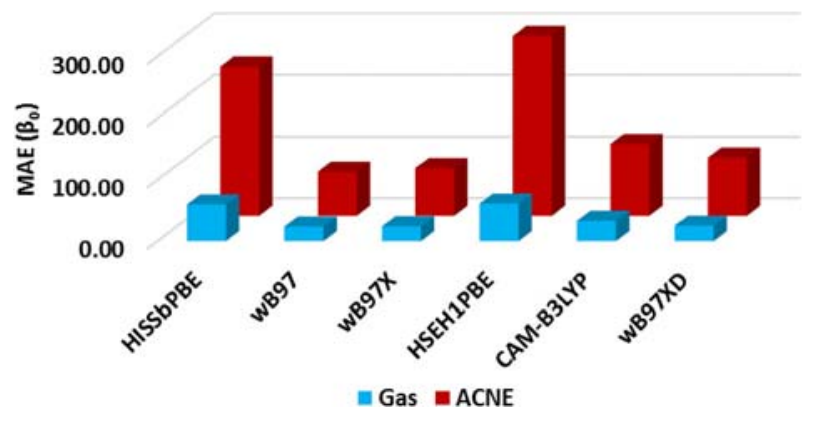

Figure 9. Hyperpolarizability $\left(\beta_{0} \times 10^{-30}\right.$ e.s.u. $)$ mean absolute error (MAE) in the gas phase and solvent acetonitrile (ACNE) by range separated hybrid functions (RSHs).

carries a nitro group para to the vinyl group. The dye 3c containing both $\mathrm{NO}_{2}$ and diethylamino group exhibited the largest hyperpolarizability in all the functionals used for comparison. This outcome signifies that the substitution pattern of donor and acceptor directly affects the magnitudes of $\alpha_{0}$ and $\beta_{0}$. In order to assess the cause of enhanced $\beta_{0}$ value, we have correlated it with the dipole moment (Figure S2, S3 and S4). All the dyes show a linear increase in dipole moment with increasing $\beta_{0}$ value which may be due to donor and acceptor group lying on the same axis (along with the direction of dipole moment) as revealed by the optimized geometry in the ground and excited state (Figure 5). These results show noticeable enhancement of CT characteristic in the studied dyes.

The GHs and RSHs give large errors in computing the polarizability $\left(\alpha_{0}\right)$ and hyperpolarizability values $\left(\beta_{0}\right)$ of the coumarin dyes under investigation. The positive values of mean absolute error (MAE) signifies that they tend to overestimate $\alpha_{0}$ and $\beta_{0}$ values. The trends in MAE in various functionals are shown in Figures $6,7,8,9$. The values of $\alpha_{0}$ obtained using from the global hybrid functionals - M06-2X, BHHLYP, M06, and PBE0 - are comparable (Figure 6). This observation is not surprising because the HF \% exchange for the hybrid BHHLYP, M06-2X, PBE0, and M06 functionals are respectively 54, 50, 27 and $25 .{ }^{54}$ Among the RSHs comparable values were obtained with the pairs of wB97 - wB97X, and CAM-B3LYP - wB97XD show more comparable precise values of $\alpha_{0}$ as compared to GHs (Figure 7). The results of $\beta_{0}$ are displayed in Table S12 and S13. The values of $\beta_{0}$ obtained from the GHs M06, $\mathrm{M} 06 \mathrm{HF}$, and PBE0 are found to be comparable with each other (Figure 8). The B3LYP functional underestimates the values of $\beta_{0}$. The trend among the GHs is found to be BHHLYP $<$ M06-2X $<$ M06 $<$ M06HF $<$ PBE0 $<$ B3LYP $<$ M06-L. As for the RSHs concerned, CAMB3LYP and wB97-XD gave comparable $\beta_{0}$ values and much closer to each other. The functionals HISSbPBE 
Table 5. Diagonal electronic and vibrational contributions to dipole polarizabilities and first hyperpolarizabilities of dyes 1a-1c, 2a-2c and 3a-3c obtained from of B3LYP/6-311++G(d,p) level in acetonitrile medium. (All values are in a.u.).

\begin{tabular}{lrrrrrrrrr}
\hline Property & $1 \mathrm{a}$ & \multicolumn{1}{c}{$1 \mathrm{~b}$} & \multicolumn{1}{c}{$1 \mathrm{c}$} & \multicolumn{1}{c}{$2 \mathrm{a}$} & \multicolumn{1}{c}{$2 \mathrm{~b}$} & \multicolumn{1}{c}{$2 \mathrm{c}$} & $3 \mathrm{a}$ & $3 \mathrm{~b}$ & $3 \mathrm{c}$ \\
\hline$\alpha_{\mathrm{xx}}^{\mathrm{e}}$ & 327.3 & 395.8 & 516.1 & 595.5 & 662.89 & 835.8 & 733.7 & 847.31 & 1124.1 \\
$\alpha_{\mathrm{yy}}^{\mathrm{e}}$ & -13.5 & 21.6 & -25.3 & -48.4 & 48.5 & -47.5 & 56.8 & 53.3 & -50.1 \\
$\alpha_{\mathrm{zz}}^{\mathrm{e}}$ & 159.4 & 174.4 & 231.0 & 258.5 & 277.1 & 322.3 & 284.6 & 300.0 & 344.4 \\
$\alpha_{\mathrm{xx}}^{\mathrm{v}}$ & 21.1 & 60.0 & 85.1 & 23.9 & 67.3 & 104.0 & 78.1 & 148.3 & 248.5 \\
$\alpha_{\mathrm{yy}}^{\mathrm{v}}$ & 7.5 & 10.3 & 15.1 & 14.0 & 18.3 & 26.6 & 21.9 & 25.0 & 27.1 \\
$\alpha_{\mathrm{zz}}^{\mathrm{v}}$ & 22.5 & 35.7 & 76.8 & 102.2 & 133.5 & 179.4 & 215.3 & 133.9 & 123.4 \\
$\alpha^{\mathrm{e}}$ & 157.7 & 197.2 & 240.6 & 268.5 & 329.5 & 370.2 & 358.4 & 400.2 & 472.8 \\
$\alpha^{\mathrm{v}}$ & 17.0 & 35.3 & 59.0 & 46.7 & 73.1 & 103.3 & 105.1 & 102.4 & 133.0 \\
$\alpha^{\mathrm{v}} / \alpha^{\mathrm{e}}$ & 9.3 & 5.6 & 4.1 & 5.7 & 4.5 & 3.6 & 3.4 & 0.3 & 3.6 \\
$\alpha^{\mathrm{e}}+\alpha^{\mathrm{v}}$ & 174.7 & 232.6 & 299.6 & 315.2 & 402.6 & 473.5 & 463.5 & 502.6 & 605.8 \\
$\beta_{\mathrm{xx}}^{\mathrm{e}}$ & 657.0 & -3027.1 & -10013.4 & 7393.9 & -1436.5 & -17812.9 & 25553.9 & -49616.8 & -113147.3 \\
$\beta_{\mathrm{yy}}^{\mathrm{e}}$ & -462.8 & 1178.7 & -1990.4 & -1085.7 & 1780.0 & -2729.5 & -2468.7 & 2784.0 & -113147.3 \\
$\beta_{\mathrm{zz}}^{\mathrm{e}}$ & 31.1 & 181.4 & 581.2 & 204.3 & 569.4 & 979.3 & -773.0 & 1259.4 & 1854.8 \\
$\beta_{\mathrm{xx}}^{\mathrm{v}}$ & 382.6 & 1638.7 & 3025.8 & -156.8 & 2231.7 & 5862.7 & -8641.0 & 16689.3 & 34918.1 \\
$\beta_{\mathrm{yy}}^{\mathrm{v}}$ & -46.8 & 43.8 & -37.0 & -203.3 & 105.7 & -89.1 & 100.9 & -70.8 & 24.6 \\
$\beta_{\mathrm{zz}}^{\mathrm{v}}$ & 0.0 & 0.0 & 233.9 & 0.2 & -0.5 & 592.2 & -0.1 & 1.3 & -74.9 \\
$\beta^{\mathrm{e}}$ & 75.1 & -555.7 & -3807.5 & 2170.8 & 304.3 & -6521.0 & 7437.4 & -15191.1 & -74813.2 \\
$\beta^{\mathrm{v}}$ & 11.9 & 560.8 & 1074.2 & -120.0 & 779.0 & 2121.9 & -2846.7 & 5539.9 & 11622.6 \\
$\beta^{\mathrm{v}} / \beta^{\mathrm{e}}$ & 0.7 & -1.0 & -3.5 & -18.1 & 0.4 & -3.1 & -2.6 & -0.4 & -6.4 \\
$\beta^{\mathrm{e}}+\beta^{\mathrm{v}}$ & 187.0 & 5.1 & -2733.3 & 2050.9 & 1083.3 & -4399.1 & 4590.6 & -9651.2 & -63190.6 \\
\hline
\end{tabular}

and HSEH1PBE overestimate the $\beta_{0}$ values as compared to the other RSHs. The functionals wB97 and wB97-X behave exactly similar manner (Figure 9). The reason for this behavior is attributed to the fact that as against RSHs, GHs do not have HF \% exchange in the longrange. This comparison of functionals suggests that the global hybrid functionals might be overestimating the hyperpolarizability results. Also, the polarizability and hyperpolarizability values were considerably lower in the absence of solvent environment. The computed values of $\alpha_{0}$ and $\beta_{0}$ of the coumarins investigated here are several times greater than that of urea. ${ }^{74}$

\subsection{Vibrational contribution to the linear and NLO response}

Vibrational anharmonicity originates from the coupling between the electronic and nuclear motions. In other words coupling between the electronic polarization and vibrational motions leads to a considerable vibrational contribution to the NLO response. DFT is an effective computational tool to study the vibrational contribution towards polarizability and hyperpolarizability of NLO materials. The vibrational contributions to static electronic polarizabilities and hyperpolarizabilities were calculated using B3LYP/6-311++G(d,p) in acetonitrile medium. The vibrational contribution to each element of $\alpha$ and $\beta$ tensor has been estimated and compared with the corresponding electronic counterpart and tabulated in Table 5. The results show that the power of an individual component indicates a significant delocalization of charges in the particular direction. It is noticed that the largest value of hyperpolarizability component is of $\beta_{x x}$ and subsequently delocalization of electron cloud is more in the $\mathrm{x}$-direction $(3 \mathrm{c}=34918.1)$. The ratios of vibrational to electronic contribution for polarizability $\left(a^{v} / a^{e}\right)$ are $9.3,5.6,4.1,5.7,4.5,3.6$, $3.4,0.3,3.6$ whereas for hyperpolarizability $\left(\beta^{v} / \beta^{e}\right)$ are $0.7,-1.0,-3.5,-18.1,0.4,-3.1,-2.6,-0.4,-6.4$ for $1 \mathrm{a}-3 \mathrm{c}$ respectively. The computed vibrational hyperpolarizability $\left(\beta^{v}\right)$ are found to be of the same order as electronic one $\left(\beta^{e}\right)$. The results confirm that the vibrational motions play a fundamental role in determining the NLO properties of these dyes.

\subsection{The correlation of BLA and BOA with NLO parameters}

BLA and BOA are the geometric and electronic parameters which depend on the length of $\pi$-conjugation, the strength of the donor-acceptor group and the surrounding media. The BLA and BOA values of $S_{0}$ and $S_{1}$ geometries were calculated from the optimized geometries of $S_{0}$ and $S_{1}$ state. The BLA and BOA parameters at $S_{0}$ and $S_{1}$ state for all the dyes are correlated with $\beta_{0}$ values in Figures 10 and f11 and the results of BLA and 

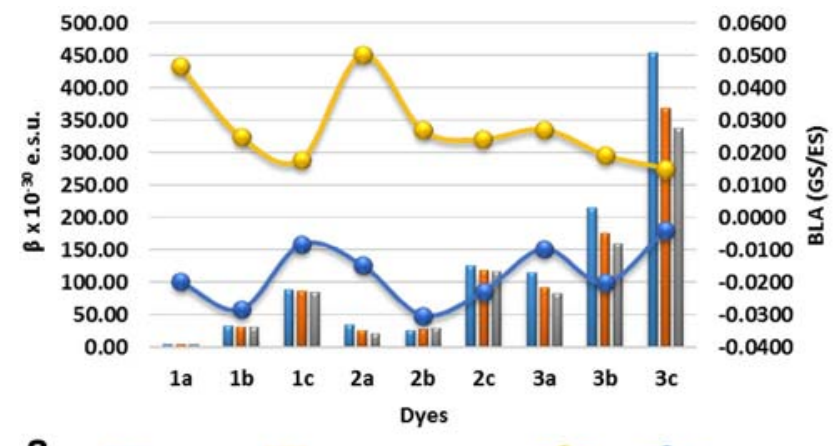

a
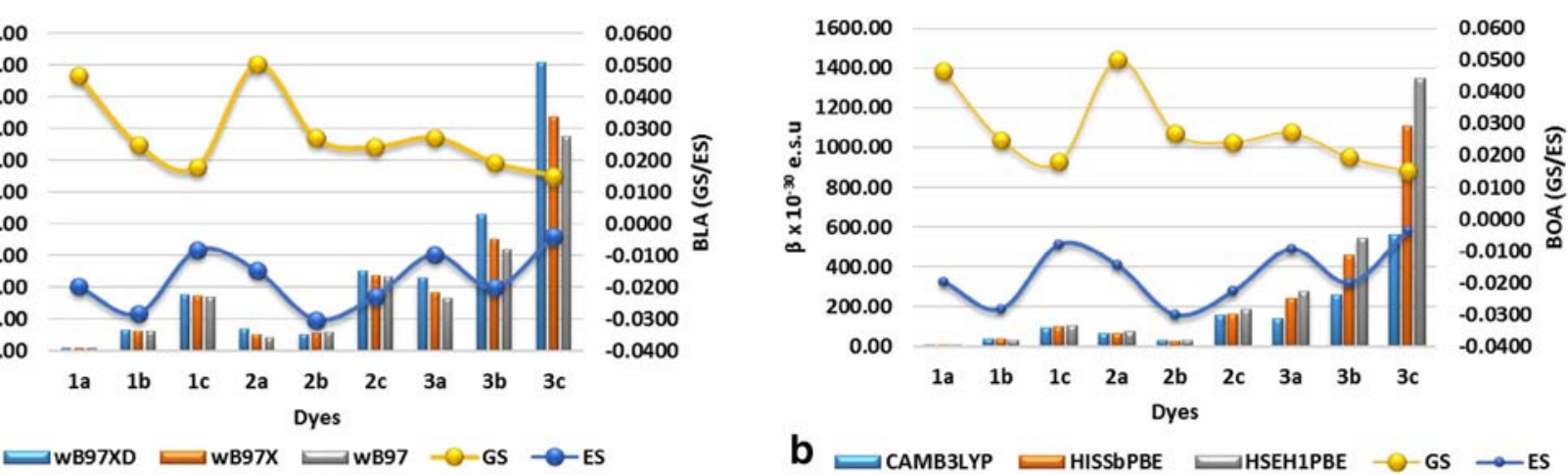

Figure 10. (a, b). BLA at ground state and excited state (GS/ES) vs. hyperpolarizability (by RSH functionals) of dyes 1a-1c, $2 \mathbf{a}-\mathbf{2} \mathbf{c}$ and $3 \mathbf{a}-\mathbf{3 c}$.
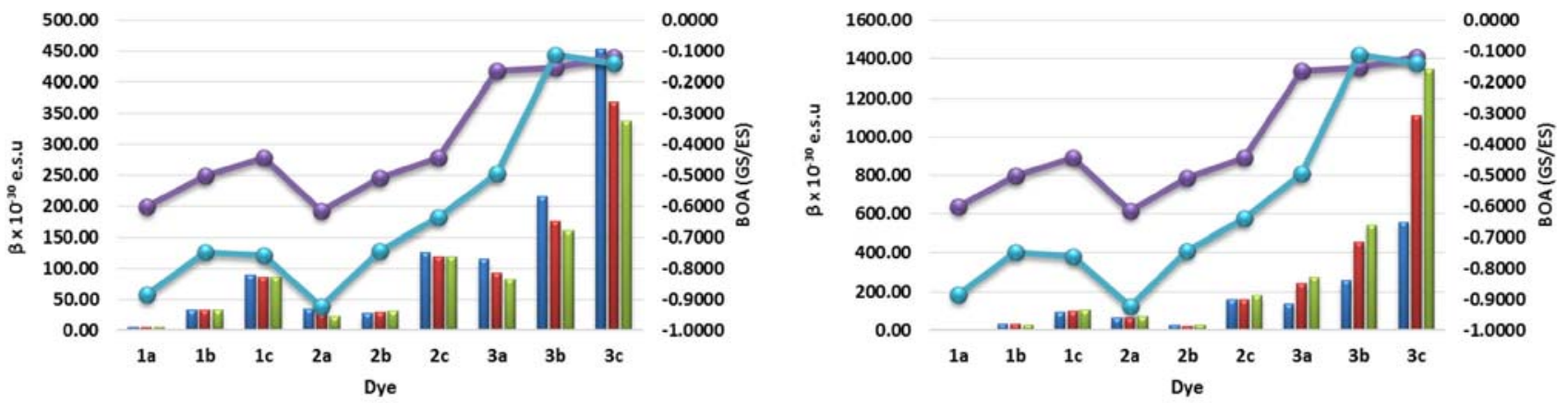

a

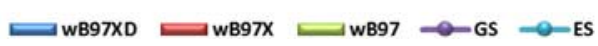

b

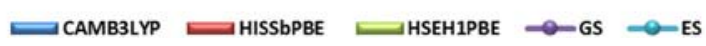

Figure 11. (a, b). BOA at ground state and excited state (GS/ES) vs. hyperpolarizability (by RSH functionals) of dyes 1a-1c, $2 \mathbf{a}-\mathbf{2} \mathbf{c}$ and $3 \mathbf{a}-\mathbf{3 c}$.

BOA are shown in Table 1. The Figures 10 and 11 show that there is a linear correlation of $\beta_{0}$ values with BLA and BOA values in $S_{0}$ and $S_{1}$ state respectively. From Table $\mathrm{S} 1$ it is seen that the BLA values decrease in the order $\mathbf{1 a}>\mathbf{1 b}>\mathbf{1 c}$ in the ground state whereas for BOA the trend is found to be the reverse. A similar trend is seen for $\mathbf{2 a}-\mathbf{2 c}$ and $\mathbf{3 a} \mathbf{a}-\mathbf{3 c}$. Moreover, in the excited state, no such regular trend is found and the values of BLA and BOA tend to zero suggesting a high degree of polarization. Greater the polarization more are the $\mu, \alpha_{0}$ and $\beta_{0}$ values which lead to a decrease in BLA and BOA (Figures 10,11). Furthermore, the magnitudes of $\mu, \alpha_{0}$ and $\beta_{0}$ increase with increasing donor-acceptor strength and increasing $\pi$-conjugation length, especially in case of 3c. The trends in $\mu, \alpha_{0}$ and $\beta_{0}$ values are in good agreement with the trends in BLA and BOA values (Figures S2, S3 and S4).

\section{Conclusions}

In summary, linear and nonlinear optical properties of styryl and vinyl coumarin dyes have been extensively studied by means of DFT and TD-DFT using global hybrid $(\mathrm{GH})$ and range separated hybrid ( $\mathrm{RSH})$ functionals using 6-311++G(d,p) basis set. The GHs overestimated $\alpha_{0}$ and $\beta_{0}$ values. The RSH functionals CAM-B3LYP, wB97, wB97-X and wB97-XD gave comparable $\alpha_{0}$ and $\beta_{0}$ values and the values are good agreement with each other. An increase in the donor strength in the sequence $-\mathrm{H}<-\mathrm{OCH}_{3}<-$ $\mathrm{N}\left(\mathrm{CH}_{2} \mathrm{CH}_{3}\right)_{2}$ enhanced charge transfer characteristics and increased NLO response in the coumarin dyes. Lowering HOMO - LUMO energy band gap brings about an increase in $\mu, \alpha_{0}$, and $\beta_{0}$. The $\beta_{0}$ value of coumarin dyes reaches the maximum as the bond length alternation (BLA) and bond order alternation (BOA) parameters tend to zero. Ratio of vibrational contribution with electronic contribution of polarizability $\left(\alpha^{v} / \alpha^{e}\right)$ and first hyperpolarizability $\left(\bar{\beta}^{v} / \bar{\beta}^{e}\right)$ decreased in the order $-\mathrm{H}<-\mathrm{OCH}_{3}<-\mathrm{N}\left(\mathrm{CH}_{2} \mathrm{CH}_{3}\right)_{2}$. High electrophilicity index suggested good photostability of the molecules. The singlet triplet energy gap analysis is found to be in good agreement with the trends in quantum yield. These coumarin dyes are proved to be the better performing NLOphores than standard urea. The coumarin dyes studied here are good candidates for the materials in nonlinear optics considering their higher static first order hyperpolarizability $\left(\beta_{0}\right)$. 


\section{Supplementary Information (SI)}

This supplementary information includes HOMO LUMO diagram, plots of dipole moment against polarizability, hyperpolarizability, geometrical parameters, natural charges, components of polarizability and hyperpolarizability obtained from different functionals. Supplementary Information is available at www.ias.ac.in/chemsci.

\section{Acknowledgements}

Kiran Avhad and Amol Jadhav are thankful to University Grant Commission, New Delhi, India for providing research fellowship.

\section{References}

1. Dalton L R, Sullivan P A and Bale D H 2010 Electric field poled organic electro-optic materials: State of the art and future prospects Chem. Rev. 11025

2. Chang C, Chen C, Chou, C, Kuo W and Jeng R 2005 Polymers for electro-optical modulation J. Macromol. Sci., Polym. Rev. 45125

3. Gieseking R L, Mukhopadhyay S, Risko C, Marder S R and Brédas J L 2014 25th Anniversary article: Design of polymethine dyes for all-optical switching applications-guidance from theoretical and computational studies Adv. Mater. 2668

4. Coe B J, Foxon S P, Harper E C, Helliwell M, Raftery J, Swanson C A, Brunschwig B S, Clays K, Franz E, Garin J, Orduna J, Horton P N and Hursthouse M B 2010 Evolution of linear absorption and nonlinear optical properties in V-shaped Ruthenium(II)-based chromophores J. Am. Chem. Soc. 1321706

5. Wu J, Wilson B A, Smith Jr D W and Nielsen S O 2014 Towards an understanding of structure-nonlinearity relationships in triarylamine-based push-pull electro-optic chromophores: The influence of substituent and molecular conformation on molecular hyperpolarizabilities $J$. Mater. Chem. C 22591

6. Yang Y, Xu H, Liu F, Wang H, Deng G, Si P, Huang H, Bo S, Liu J, Qiu L, Zhen Z and Liu X 2014 Synthesis and optical nonlinear property of Y-type chromophores based on double-donor structures with excellent electrooptic activity J. Mater. Chem. C 25124

7. Kutuvantavida Y, Williams G V M, Bhuiyan M D H, Raymond S G and Kay A J 2015 Effects of chromophore conjugation length and concentration on the photostability of indoline-based nonlinear optical chromophore/polymer films J. Phys. Chem. C 1193273

8. Gheorma I L and Gopalakrishnan G K 2007 Flat frequency comb generation with an integrated dual-parallel modulator IEEE Photonics Technol. Lett. 191011

9. Liu J, Gao W, Kityk I V, Liu X and Zhen Z 2015 Optimization of polycyclic electron-donors based on julolidinyl structure in push-pull chromophores for second order NLO effects Dyes Pigments 12274

10. Gryl M, Kozieł M, Stadnicka K, Matulková I, Němec I, Tesařová N and Němec P 2013 Lidocaine barbiturate:
A promising material for second harmonic generation CrystEngComm 153275

11. Tathe A B and Sekar N 2016 Red emitting NLOphoric 3-styryl coumarins: Experimental and computational studies Opt. Mater. (Amst). 51121

12. Derkowska B, Mulatier J C, Fuks I, Sahraoui B, Phu X N and Andraud C 2001 Third-order optical nonlinearities in new octupolar molecules and their dipolar subunits $J$. Opt. Soc. Am. B 18610

13. Papagiannouli I, Iliopoulos K, Gindre D, Sahraoui B, Krupka O, Smokal V, Kolendo A and Couris S 2012 Third-order nonlinear optical response of push-pull azobenzene polymers Chem. Phys. Lett. 554107

14. Sahraoui B, Luc J, Meghea A, Czaplicki R, Fillaut J L and Migalska-Zalas A 2009 Nonlinear optics and surface relief gratings in alkynyl-ruthenium complexes $J$. Opt. A Pure Appl. Opt. 1124005

15. Lin T C, Cole J M, Higginbotham A P, Edwards A J, Piltz R O, Perez-Moreno J, Seo J Y, Lee S C, Clays K and Kwon O P 2013 Molecular origins of the high-performance nonlinear optical susceptibility in a phenolic polyene chromophore: Electron density distributions, hydrogen bonding, and ab initio calculations $J$. Phys. Chem. C 1179416

16. Tathe A B and Sekar N 2016 NLOphoric red emitting bis coumarins with O-BF2-O core-synthesis, photophysical properties and DFT studies J. Fluoresc. 26471

17. Abraham E, Oberlé J, Jonusauskas G, Lapouyade R and Rullière C 1997 Photophysics of 4-dimethylamino 4/cyanostilbene and model compounds: Dual excited states revealed by sub-picosecond transient absorption and kerr ellipsometry Chem. Phys. 214409

18. Grabowski Z R, Rotkiewicz K and Rettig W 2003 Structural changes accompanying intramolecular electron transfer: Focus on twisted intramolecular charge-transfer states and structures Chem. Rev. 1033899

19. Pines D, Pines E and Rettig W 2003 Dual fluorescence and excited-state structural relaxations in donor-acceptor stilbenes J. Phys. Chem. A 107236

20. Singh A K, Darshi M and Kanvah S $2000 \alpha, \omega$ diphenylpolyenes cabable of exhibiting twisted intramolecular charge transfer fluorescence: A fluorescence and fluorescence probe study of nitro- and nitrocyano-substituted 1,4-diphenylbutadienes J. Phys. Chem. A 104464

21. Carlotti B, Flamini R, Kikaš I, Mazzucato U and Spalletti A 2012 Intramolecular charge transfer, solvatochromism and hyperpolarizability of compounds bearing ethenylene or ethynylene bridges Chem. Phys. 4079

22. Li C, Li M, Li Y, Zhang Y, Cai Z, Shi Z, Wang X, Zhang D and Cui Z 2016 Improved poling efficiency of polyurethanes containing spindle-like chromophores by a functional group tuning for nonlinear optic (NLO) materials RSC Adv. 618178

23. Li M, Huang S, Zhou X H, Zang Y, Wu J, Cui Z, Luo J and Jen A K Y 2015 Poling efficiency enhancement of tethered binary nonlinear optical chromophores for achieving an ultrahigh $\mathrm{N}^{3} \mathrm{R}_{33}$ figure-of-merit of 2601 $\mathrm{Pm} \mathrm{V}{ }^{-1}$ J. Mater. Chem. C 36737

24. Kim T D, Kang J W, Luo J, Jang S H, Ka J W, Tucker N, Benedict J B, Dalton L R, Gray T, Overney R M, Park D H, Herman W N and Jen A K Y 2007 Ultralarge and 
thermally stable electro-optic activities from supramolecular self-assembled molecular glasses $J$. Am. Chem. Soc. 129488

25. Zhang X, Li M, Shi Z, Wan Y, Zhao L, Jin R, Wang X, Zhang D, Yi M and Cui Z 2011 Design, synthesis, and characterization of crosslinkable doped NLO materials based on polyurethanes containing spindle-type chromophores Macromol. Chem. Phys. 212879

26. Cheng Y J, Luo J, Huang S, Zhou X, Shi Z, Kim T D, Bale D H, Takahashi S, Yick A, Polishak B M, Jang S H, Dalton L R, Reid P J, Steier W H and Jen A K Y 2008 Donor-acceptor thiolated polyenic chromophores exhibiting large optical nonlinearity and excellent photostability Chem. Mater. 205047

27. Moeckli P 1980 Preparation of some new red fluorescent 4-cyanocoumarin dyes Dyes Pigments 13

28. Griffiths J, Millar V and Bahra G S 1995 The influence of chain length and electron acceptor residues in 3-substituted 7-N,N-diethylaminocoumarin dyes Dyes Pigments 28327

29. Lanke S K and Sekar N 2016 Aggregation induced emissive carbazole-based push pull NLOphores: Synthesis, photophysical properties and DFT studies Dyes Pigments 12482

30. Lanke S K and Sekar N 2015 Rigid coumarins: A complete DFT, TD-DFT and non linear optical property study J. Fluoresc. 251469

31. Lindasay 1973 United States Patent 191, No. 1984

32. Moylan C R 1994 Molecular hyperpolarizabilities of coumarin dyes J. Phys. Chem. 9813513

33. Moerner W E and Silence S M 1994 Polymeric photorefractive materials Chem. Rev. 94127

34. Tathe A B, Gupta V D and Sekar N 2015 Synthesis and combined experimental and computational investigations on spectroscopic and photophysical properties of red emitting 3-styryl coumarins Dyes Pigments 11949

35. Huang S T, Jian J L, Peng H Z, Wang K L, Lin C M, Huang C H and Yang T C K 2010 The synthesis and optical characterization of novel iminocoumarin derivatives Dyes Pigments $\mathbf{8 6} 6$

36. Tathe A B and Sekar 2016 N Red-emitting NLOphoric carbazole-coumarin hybrids-synthesis, photophysical properties and DFT studies Dyes Pigments 129174

37. Lanke S K and Sekar 2015 N Rigid coumarins: A complete DFT, TD-DFT and non linear optical property study J. Fluoresc. 251469

38. Brédas J L 1985 Relationship between band gap and bond length alternation in organic conjugated polymers J. Chem. Phys. 823808

39. Roncali J 2007 Molecular engineering of the band gap of $\pi$-conjugated systems: Facing technological applications Macromol. Rapid Comm. 281761

40. Mullekom H A M van, Vekemans J A J M, Havinga and Meijer E W 2001 Developments in the chemistry and band gap engineering of donor-acceptor substituted conjugated polymers Mat. Sci. Eng. R 321

41. Marder S R, Gorman C B, Tiemann B G and Cheng L T 1993 Stronger acceptors can diminish nonlinear optical response in simple donor-acceptor polyenes J. Am. Chem. Soc. 1153006

42. Bouit P A, Aronica C, Toupet L, Guennic B Le, Andraud $\mathrm{C}$ and Maury O 2010 Continuous symmetry breaking induced by ion pairing effect in heptamethine cyanine dyes: Beyond the cyanine limit J. Am. Chem. Soc. 132 4328

43. Meyers F, Marder S R, Pierce B M and Bredas J L 1994 Electric field modulated nonlinear optical properties of donor-acceptor polyenes: Sum-over-states investigation of the relationship between molecular polarizabilities (alpha, beta, and gamma) and bond length alternation J. Am. Chem. Soc. 11610703

44. Kwon O P, Kwon S J, Jazbinsek M, Seo J Y, Kim J T, Seo J I, Lee Y S, Yun H and Gunter P 2011 Phenolic polyene crystals with tailored physical properties and very large nonlinear optical response Chem. Mater. 23239

45. Kohn W and Sham L J 1965 Self-consistent equations including exchange and correlation effects Phys. Rev. 1401133

46. Frisch M J, Trucks G W, Schlegel H B, Scuseria G E, Robb M A, Cheeseman J R, Scalmani G, Barone V, Mennucci B, Petersson G A, Nakatsuji H, Caricato M, Li X, Hratchian H P, Izmaylov A F, Bloino J, Zheng G, Sonnenberg J L, Hada M, Ehara M, Toyota K, Fukuda R, Hasegawa J, Ishida M, Nakajima T, Honda Y, Kitao O, Nakai H, Vreven T, Montgomery Jr J A, Peralta J E, Ogliaro F, Bearpark M, Heyd J J, Brothers E, Kudin K N, Staroverov V N, Keith T, Kobayashi R, Normand J, Raghavachari K, Rendell A, Burant J C, Iyengar S S, Tomasi J, Cossi M, Rega N, Millam J M, Klene M, Knox J E, Cross J B, Bakken V, Adamo C, Jaramillo J, Gomperts R, Stratmann R E, Yazyev O, Austin A J, Cammi R, Pomelli C, Ochterski J W, Martin R L, Morokuma K, Zakrzewski V G, Voth G A, Salvador P, Dannenberg J J, Dapprich S, Daniels A D, Farkas O, Foreman J B, Ortiz J V, Cioslowski J and Fox D J 2010 G. 09; Revision C.01, Gaussian, Inc., Wallingford, CT

47. Lee C, Yang W and Parr R G 1988 Development of the Colle-Salvetti correlation-energy formula into a functional of the electron density Phys. Rev. B 37785

48. Becke A D 1993 Density-functional thermochemistry. III. The role of exact exchange J. Chem. Phys. 985648

49. Stephens P J, Devlin F J, Chabalowski C F and Frisch M J 1994 Ab initio calculation of vibrational absorption and circular dichroism spectra using density functional force fields J. Phys. Chem. 9811623

50. Petersson G A, Bennett A, Tensfeldt T G, Al-Laham M A, Shirley W A and Mantzaris J A 1988 Complete basis set model chemistry. I. The total energies of closed-shell atoms and hydrides of the first-row elements J. Chem. Phys. 892193

51. Runge E and Gross E K U 1984 Density-functional theory for time-dependent systems Phys. Rev. Lett. 52997

52. Tomasi J, Mennucci B and Cammi R 2005 Quantum mechanical continuum Solvation models Chem. Rev. 105 2999

53. Vidya S, Ravikumar C, Hubert Joe I, Kumaradhas P, Devipriya B and Raju K 2011 Vibrational spectra and structural studies of nonlinear optical crystal ammonium D, L-tartrate: A density functional theoretical approach J. Raman Spectrosc. 42676

54. Howard J C, Enyard J D and Tschumper G S 2015 Assessing the accuracy of some popular DFT methods for computing harmonic vibrational frequencies of water clusters J. Chem. Phys. 143214103 
55. Henderson T M, Izmaylov A F, Scuseria G E and Savin A 2008 Assessment of a Middle-Range Hybrid Functional J. Chem. Theory Comput. 41254

56. Peverati R and Truhlar D G 2014 Quest for a universal density functional: The accuracy of density functionals across a broad spectrum of databases in chemistry and physics Philos. T. Roy. Soc. A 37220120476

57. Laurent A D and Jacquemin D 2013 TD-DFT benchmarks: A review Int. J. Quantum Chem. 113 2019

58. Caricato M, Trucks G W, Frisch M J and Wiberg K B 2010 Electronic transition energies: A study of the performance of a large range of single reference density functional and wave function methods on valence and rydberg states compared to experiment J. Chem. Theory Comput. 6370

59. Marom N, Tkatchenko A, Rossi M, Gobre V V, Hod O, Scheffler M and Kronik L 2011 Dispersion interactions with density-functional theory: Benchmarking semiempirical and interatomic pairwise corrected density functionals J. Chem. Theory Comput. 7 3944

60. Bhattacharya D, Shil S, Misra A, Bytautas L and Klein D J 2015 Photomagnetic and nonlinear optical properties in cis-trans green fluoroprotein chromophore coupled bisimino nitroxide diradicals Int. J. Quantum Chem. 115 1561

61. Nénon S, Champagne B and Spassova M I 2014 Assessing long-range corrected functionals with physicallyadjusted range-separated parameters for calculating the polarizability and the second hyperpolarizability of polydiacetylene and polybutatriene chains Phys. Chem. Chem. Phys. 167083

62. Eriksson E S and Eriksson L A 2011 Predictive power of long-range corrected functionals on the spectroscopic properties of tetrapyrrole derivatives for photodynamic therapy Phys. Chem. Chem. Phys. 137207

63. Benassi E 2017 Benchmarking of density functionals for a soft but accurate prediction and assignment of $1 \mathrm{H}$ and $13 \mathrm{C}$ NMR chemical shifts in organic and biological molecules J. Comput. Chem. 3887
64. Zhao Y and Truhlar D G 2011 Density functional theory for reaction energies: Test of meta and hybrid meta functionals, range-separated functionals, and other highperformance functionals J. Chem. Theory Comput. 7669

65. Gerber I C and Ángyán J G 2005 Hybrid functional with separated range Chem. Phys. Lett. 415100

66. Salzner U and Aydin A 2011 Improved prediction of properties of $\pi$-conjugated oligomers with rangeseparated hybrid density functionals J. Chem. Theory Comput. 72568

67. Baer R, Livshits E and Salzner U 2010 Tuned rangeseparated hybrids in density functional theory Annu. Rev. Phys. Chem. 6185

68. Refaely-Abramson S, Baer R and Kronik L 2011 Fundamental and excitation gaps in molecules of relevance for organic photovoltaics from an optimally tuned rangeseparated hybrid functional Phys. Rev. B $\mathbf{8 4} 75144$

69. Meganathan C, Sebastian S, Kurt M, Lee K W and Sundaraganesan N 2010 Molecular structure, spectroscopic (FTIR, FTIR gas phase, FT-raman) first-order hyperpolarizability and HOMO-LUMO analysis of 4methoxy-2-methyl benzoic acid J. Raman Spectrosc. 41 1369

70. Fu Y, Shen W and Li M 2008 Geometries and electronic structures of co-oligomers and co-polymers based on tricyclic nonclassical thiophene: A theoretical study Macromol. Theor. Simul. 17385

71. Gordo J, Avó J, Parola A J, Lima J C, Pereira A and Branco P S 2011 Convenient synthesis of 3-vinyl and 3-styryl coumarins Org. Lett. 135112.

72. Mahalakshmi $G$ and Balachandran V 2015 NBO, HOMO, LUMO Analysis and vibrational spectra (FTIR and FT raman) of 1-amino 4-methylpiperazine using ab initio HF and DFT methods Spectrochim. Acta Part A 135321

73. Geerlings P, De Proft F and Langenaeker W 2003 Conceptual density functional theory Chem. Rev. 1031793

74. Arivazhagan M, Kavitha R and Subhasini V P 2014 Conformational analysis, UV-VIS, MESP, NLO and NMR studies of 6-methoxy-1,2,3,4-tetrahydronaphthalene Spectrochim. Acta Part A 128701 